\title{
A developing Asia emission trading scheme (Asia ETS)
}

\author{
Emanuele Massetti ${ }^{*}$, Massimo Tavoni \\ Fondazione Eni Enrico Mattei (FEEM), Italy \\ Euro-Mediterranean Ceter for Climate Change (CMCC), Italy
}

\section{A R T I C L E I N F O}

\section{Article history:}

Received 3 June 2011

Received in revised form 27 December 2011

Accepted 8 February 2012

Available online $\mathrm{xxxx}$

\section{JEL classification:}

C68

Q52

Q54

Q58

Keywords:

Climate change

Developing Asia

Mitigation scenarios

Emission trading

EU-ETS

Equity

\begin{abstract}
A B S T R A C T
This paper provides a model assessment of the role of developing Asia in the context of climate change policies. We diagnose the potential response of Asian economies to the imposition of various climate policies, showing that if we were to equally price carbon across the world roughly half of the abatement would occur in developing Asia. We show that such autarkic measures would be consistent with the policy targets put forward by the Major Economies Forum but would not necessarily be equitable. We thus propose a fragmented cap-and-trade scheme with a specific regional market for developing Asia, the Asian Emission Trading Scheme (Asia ETS). We assess the role of the Asia ETS on the macro-economy and international transfers vis-à- vis the standard case of global trading. Our results indicate that creating two large trading markets would result in small global efficiency losses, while at the same time generating more reasonable regional incentives and transfers.
\end{abstract}

(c) 2012 Published by Elsevier B.V.

\section{Introduction}

It is now an established fact that the role of developing Asia will be crucial in the context of climate change control. The rapid economic expansion of many Asian economies has been accompanied by a similar, and in some cases even higher, growth of energy consumption, leading to a significant increase of carbon intensive capital and of greenhouse gas emissions in recent years. The most notable case is of course China, which a few years ago became the world top emitting country, and whose emissions in 2008 are already 25\% above the second largest emitter, the United States. It is not only China, though. The whole region is expected to see its share of global emissions increasing.

The stage of economic development of the region, which on average is approaching but still below the 5000 USD/capita threshold, believed to mark the real take-off of energy consumption, also suggests that important carbon abatement opportunities can be implemented before a too large fraction of carbon intensive investments are undertaken, locking in the medium term possibilities to shift away from a carbon intensive energy system. The region also

\footnotetext{
* Corresponding author at: Fondazione Eni Enrico Mattei, C.so Magenta, 63, 20123 Milano, Italy. Tel.: + 390252036814.

E-mail address: emanuele.massetti@feem.it (E. Massetti).
}

hosts considerable potential for deployment of low carbon options such as renewables, avoided deforestation, energy efficiency, and so forth. Indeed, modelling results have highlighted the importance of involving developing countries, and foremost Asia, in the task of mitigation. For example, the EMF22 comparison exercise (Clarke et al., 2009) has shown that the feasibility and costs of climate stabilization would become prohibitive without an effective and prompt collaboration between developed and developing countries.

Motivated by the increasingly alarming output of the climate science research, policy and modelling of climate change has in recent years increasingly focused on the assessment of stringent climate stabilization targets, such as those consistent with the objective of limiting temperature increase to 2 degree Celsius $\left(2{ }^{\circ} \mathrm{C}\right)$ with adequate probability. From a modelling viewpoint, the role of technologies that allow to comply with a low future carbon budget has received particular attention. For example, the role of negative emissions via biomass burning and Carbon Capture and Storage (CCS) has been shown to be very important for this class of scenarios (see for example Azar et al., 2010), with significant repercussions on the economic estimates of climate policies (Tavoni and Tol, 2010).

However, translating global climate goals into regional commitments becomes progressively more problematic with an increasing stringency of the climate target, since a smaller carbon budget is left to be shared. For example, in order to achieve $2{ }^{\circ} \mathrm{C}$ policies an indicative target of $-50 \%$ in 2050 (with respect to 2005 levels) has been identified. In 
2009 the G8 combined this level of ambition with a target for developed countries ( -80 to $-95 \%$ ), thus effectively determining the obligations of the developing world as well. Similarly, the OECD International Energy Agency (IEA) recently stated that China's emissions need to peak by 2020 if the world is to meet the above mentioned 2050 target. $^{1}$ Not surprisingly, the reaction from developing countries has not been favourable, as such obligations are feared to come at a cost in terms of economic growth.

Thus, from a research standpoint, there is a need to discuss under what conditions stringent climate targets and a reasonably just allocation of effort can be jointly met (Tavoni et al., 2011). Asia is the key on both fronts, since it is a fast growing and emitting region, which also hosts a large share of the global population, including many people still in poverty. On the front of mitigation, it is imperative to understand the drivers of emissions in a baseline case, and to compare this counterfactual to the abatement opportunities that the region offers. As for the repartition of the global climate mitigation effort, it is important to evaluate acceptable levels of regional commitments and to design policy instruments that facilitate this process.

This paper aims at contributing to both issues. Within the context of the Asia Modeling Exercise (AME) we run a set of coordinated scenarios that include a baseline and a series of domestic climate policies. We complement this analysis with the issue of burden sharing, focusing on the role of international carbon quota policies. Specifically, we confront the standard, idealized case of a global carbon market with one in which this coexists with a specific carbon market for developing Asia, the Asia Emission Trading Scheme (Asia ETS).

A series of research questions are at the core of this analysis. What is the role of developing Asia in shaping global emissions and what are their abatement opportunities? How far is the baseline scenario from the 2050 targets discussed in policy, and what is the regional effort required to achieve them? How can we combine efficiency and equity, while maximizing political acceptability?

Unsurprisingly, the paper falls short of providing definitive answers to all of these important questions. Nonetheless, it strives to provide an assessment of the role of Asia in the context of climate stabilization that considers both the technological, economic and equity aspects at the same time.

The paper is structured into five sections. In the next one, we quickly describe the methodology and the set-up of the experiment. Then, we provide a diagnosis of Asia emissions under a Business-as-Usual as well as under domestic climate policies. In Sections 4 and 5, we present and discuss the role of an the Asia ETS. Conclusions are summarized in Section 6 .

\section{Model and scenario set-up}

The analysis throughout the paper is carried out with the WITCH integrated assessment model (Bosetti et al., 2006 and www. witchmodel.org). WITCH is an inter-temporal, optimal growth model, with a game-theoretical set-up that allows to model multiple externalities. In particular, it features the climate as well as the technology externalities, the latter via international spillovers of knowledge and experience. For the sake of this paper, the climate policy scenarios in WITCH are run in two fashions. The cases of carbon taxation are implemented by imposing a pre-determined carbon tax whose revenues are fully recycled back into the economy. The cases of emission quotas, allocated to the model 13 regions, are implemented through a carbon trading market modelled in an iterative fashion, through a tâtonnement process in which demand and supply are matched by adjusting the carbon prices till the market clears. The

\footnotetext{
${ }^{1}$ http://www.reuters.com/article/2010/07/16/us-china-carbon-iea-idUSTRE66F2XC
} 20100716
Table 1

The scenarios.

\begin{tabular}{|c|c|c|}
\hline $\begin{array}{l}\text { Scenario } \\
\text { acronym }\end{array}$ & Scenario name & Scenario description \\
\hline $1 \mathrm{a}$ & Reference & Business-as-usual (BaU) \\
\hline $2 \mathrm{a}$ & $\begin{array}{l}\mathrm{CO}_{2} \text { price } \$ 10 \\
\text { (5\% p.a.) }\end{array}$ & Low carbon tax (starting at $7 \$ / \mathrm{tCO}_{2}$ in 2013) \\
\hline $2 \mathrm{~b}$ & $\begin{array}{l}\mathrm{CO}_{2} \text { price } \$ 30 \\
(5 \% \text { p.a. })\end{array}$ & Medium carbon tax (starting at $21 \$ / \mathrm{tCO}_{2}$ in 2013) \\
\hline $2 c$ & $\begin{array}{l}\mathrm{CO}_{2} \text { price } \$ 50 \\
(5 \% \text { p.a.) }\end{array}$ & High carbon tax (starting at $36 \$ / \mathrm{tCO}_{2}$ in 2013) \\
\hline $3 a$ & $3.7 \mathrm{~W} / \mathrm{m}^{2} \mathrm{NTE}$ & $\begin{array}{l}\text { Stabilization at } 3.7 \mathrm{~W} / \mathrm{m}^{2} \text { implemented as a carbon } \\
\operatorname{tax}\end{array}$ \\
\hline $3 b$ & $2.6 \mathrm{~W} / \mathrm{m}^{2} \mathrm{OS}$ & $\begin{array}{l}\text { Stabilization at } 2.6 \mathrm{~W} / \mathrm{m}^{2} \text { implemented as a carbon } \\
\text { tax }\end{array}$ \\
\hline $4 a$ & & $\begin{array}{l}\text { Stabilization at } 2.6 \mathrm{~W} / \mathrm{m}^{2} \text { implemented as a quota } \\
\text { system with one global carbon market }\end{array}$ \\
\hline $4 \mathrm{~b}$ & & $\begin{array}{l}\text { Stabilization at } 2.6 \mathrm{~W} / \mathrm{m}^{2} \text { implemented as a quota } \\
\text { system with two carbon markets (ATS and Rest of } \\
\text { the World ETS) }\end{array}$ \\
\hline
\end{tabular}

model generates financial flows in or out of the regions depending on their carbon trading position and the price of $\mathrm{CO}_{2}$. Obviously, both systems are efficient because they equalize the regional marginal abatement cost to the carbon tax in the first case and the price of permits in the second (which for the same target are identical). However, they differ in that the quota system allows for compensation of the costs of abatement by allowing financial transfers, in proportion to the allocation of permits.

Eight scenarios are envisaged in this analysis, as described in Table 1 . The first five scenarios are in adherence to the ones common to the AME exercise (Calvin et al., this issue): a Business-as-Usual, followed by 3 carbon tax cases, with values growing at the same interest rate but starting from different values in the first implementation period; and two stabilization scenarios, at 3.7 and $2.6 \mathrm{~W} / \mathrm{m}^{2}$, also implemented as a domestic carbon tax equal for all regions. In addition, we present two scenarios, focusing only on the most ambitious climate stabilization objective (the only one compatible with a $2{ }^{\circ} \mathrm{C}$ policy), both of which implemented through an international quota system with trading of permits. The first scenario features a single global carbon market. In the second, we consider two carbon markets, one that operates only for the developing Asia regions ${ }^{2}$ and another for the rest of the world.

With this scenario set-up we can explore the questions raised in the introduction, by comparing policies with different levels of ambition $(2 a, 2 b, 2 c, 3 a$ and $3 b, 4 a, 4 b)$, or different implementation designs $(3 b, 4 a, 4 b)$. All cases but the last are idealised ones because they guarantee an efficient distribution of the abatement effort (though the only climate externality is taken care of, and thus even these scenarios are not necessarily Pareto optimal).

In order to run the $2.6 \mathrm{~W} / \mathrm{m}^{2}$ (450 ppm-eq) scenario, the WITCH model had to be amended to include options that allow $\mathrm{CO}_{2}$ to be absorbed from the atmosphere. Technically, this was done by including the technology of biomass burning and storage of $\mathrm{CO}_{2}$ in the ground (BECCS). Among the various carbon dioxide removal technologies, BECCS is considered to be a promising one, though only provided sufficient land is available to avoid clashed with other, arguably more fundamental, competing claims on land. Negative emissions technologies are key to achieving low carbon stabilization scenarios (Clarke et al.,

\footnotetext{
${ }^{2}$ In the model these are: China, India, South East Asia (EASIA) and South Asia (SASIA). South East Asia largely corresponds to the East Asia \& Pacific region of the World Bank. We exclude China; we include New Caledonia, Brunei, French Polynesia, Guam, Northern Mariana Islands, Singapore, all in the World Bank non-OECD high income region. South Asia includes: Afghanistan, Bangladesh, Bhutan, Maldives, Nepal Pakistan and Sri Lanka.
} 
2009), but are also highly speculative ones. Their inclusion thus signifies this is a technology optimistic modelling set-up.

The cost of the biomass feedstock is determined by WITCH on the basis of regional supply cost curves obtained by the land use GLOBIOM (Havlik et al., 2010) model. GLOBIOM accounts for residual emissions associated with the full life cycle of growing, harvesting and transporting the biomass. The power generation technology is assimilated to integrated gasification of coal, with specific penalties on costs and performance obtained from the techno-economic literature (Azar et al., 2006; Gough and Upham, 2010; Hansson et al., 2009; IEAGHG, 2009; Rhodes and Keith, 2005). ${ }^{3}$ As for the storage of $\mathrm{CO}_{2}$, the model features endogenous regional supply cost curves with no limits to the total absorption potential.

\section{Diagnosing the response of Asian economies to carbon policies}

We begin by analysing the results of the first 6 scenarios, those shared with the AME exercise. The results in terms of global emission pathways are reported in Fig. 1. WITCH Business-as-Usual (1a) foresees a continued use of fossil fuels and thus substantial growth in emissions, which reach a plateau at the end of the century. On the other hand, the various climate policies have a profound, and distinctively different, impact on the emissions profiles. Even the more lenient carbon tax (2a) is able to reduce emissions considerably, with a peak year around mid-century, when the carbon tax is set at about $40 \$ / \mathrm{tCO}_{2}$. This is a result of the inter-temporal nature of the model, that anticipates the exponentially growing tax value (which for $2 \mathrm{a}$ reaches $500 \$ / \mathrm{tCO}_{2}$ at the end of the century). As expected, increasing the level of the tax increases abatement and anticipates the peak year of emissions, though the abatement gains are less than proportional, as a results of the nonlinear marginal abatement costs of the model and the fact that the tax are also raised non linearly (the medium tax is roughly 3 times higher than the low one, and the high tax only 1.6 times the medium one). Both the medium and high taxes allow energy $\mathrm{CO}_{2}$ emissions to be zeroed at the end of the century.

In terms of global climate change implications, the carbon taxes provide substantial reductions of concentrations of greenhouse gases (GHGs), with the medium and high taxes being able to lower them below those of the less stringent stabilization scenario (3a), though in both cases the concentration target consistent with a $2{ }^{\circ} \mathrm{C}$ policy (scenario $3 \mathrm{~b}$ ) is missed. It also interesting to observe that for both of the two higher taxes, as well as for the more stringent stabilization scenario, maximum GHGs concentrations are attained before the end of the century, meaning that they lead to so-called overshoot trajectories (Table 2).

Turning our attention to the specific case of developing Asian countries, Fig. 2 provides a snapshot of the abatement that the 5 AME climate policy scenarios have on the 4 Asian regions. ${ }^{4}$ As expected, given its size in terms of both population and economic activities, China is the country where the largest absolute emissions reductions occur. India is second, followed closely by South-East Asia: this is a region hosting roughly half of the population of India (almost 650 million people in 2005), but with a total economic activity which is now some $25 \%$ higher than the Indian one, given the more advanced stage of development of countries such as Malaysia, Thailand, Indonesia etc. It is also a region with plentiful abatement opportunities, especially for what regards avoided deforestation and bio-energy.

\footnotetext{
${ }^{3}$ Investment cost in integrated gasification combined cycle (IGCC) coal power plants is equal to $3172 \mathrm{USD} / \mathrm{kW}, 3.0-1.5$ times higher than the investment cost used in the model for traditional pulverized coal power plants. We assume that biomass is used together with coal. In 2015 the amount of biomass cannot exceed $20 \%$ of total fuel use. In 2050 the share exogenously grows to $57 \%$ and in 2100 biomass can be used alone. The efficiency of IGCC power plants is equal to 0.4 when used only with coal. It is 0.35 if used with biomass only. The capture rate of CCS is equal to $90 \%$.

${ }^{4}$ For a detailed analysis of BaU and carbon tax emissions scenarios with the WITCH model for China and India see Massetti (2011) and Carraro and Massetti (2011).
}

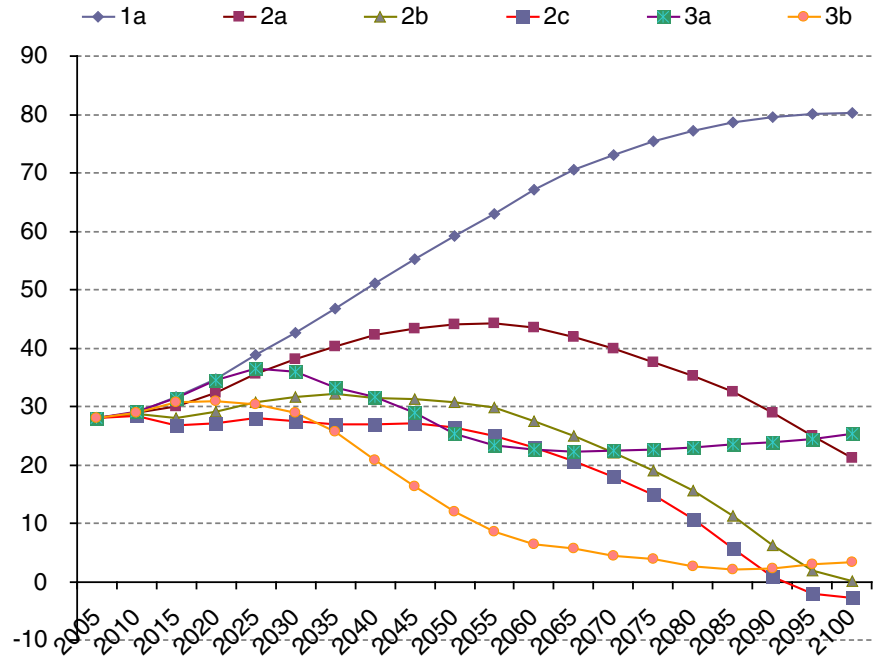

Fig. 1. Global, energy related $\mathrm{CO}_{2}$ emissions.

Similarly to what was shown for the global picture, the abatement brought about by the medium $(2 b)$ and high taxes $(2 c)$ resembles that of the two stabilization scenarios ( $3 a, 3 b$ ) respectively. The milder tax achieves roughly half and one third of the mitigation of the same scenarios respectively. In terms of total contribution of the developing Asian regions to global abatement, the share of global abatement is surprisingly constant across all the 5 climate policy scenarios. China provides roughly $30 \%$ of global mitigation, the rest of developing Asia $17 \%$, and the remaining is equally split among OECD countries and the rest of the world.

The impact of the climate policies on regional mitigation can also be appreciated in Fig. 3 and in Fig. 4, where we focus on the year 2050, an important signpost for policy. The charts show how the various policies are able to progressively reduce emissions with respect to today's levels. It is instructive to notice that the stringent stabilization scenario $3 b$ entails emission reductions which are in line with the proposal of the G8 and Major Economies Forum: global emissions are roughly halved by 2050 , and the OECD takes on an obligation close to $80 \%$ (Fig. 3; see also Carraro and Massetti, 2011; Massetti, 2011).

Thus, according to our numerical assessment, the G8 burden sharing proposal for 2050 is one in which a $2{ }^{\circ} \mathrm{C}$ consistent policy is implemented through domestic action achieved by uniformly pricing carbon across the world. As already noted, this scheme could sidestep the question of a just and fair allocation of allowances to emit, and has been criticized by developing countries exactly on these grounds.

Fig. 4 displays the percentage deviation of emissions from the $\mathrm{BaU}$ in the 5 AME scenarios and reveals the large mitigation effort that developing Asia must do to comply with the proposed G8 and MEF scheme. With bustling economies and growing populations all regions have a fast growing demand of energy which causes a constantly rising pattern of emissions. The $3 \mathrm{~b}$ scenario requires them to cut emissions abruptly from the BaU trend. China and East Asia must reduce emissions by roughly $80 \%$, as the OECD economies. India's progress on mitigation would seem modest if emissions in 2050 were compared to their level in 2005 (Fig. 3); quite the opposite, it entails a remarkable $70 \%$ contraction with respect to the $\mathrm{BaU}$.

Table 2

GHGs concentrations expressed in ppm of $\mathrm{CO}_{2} \mathrm{eq}$.

\begin{tabular}{lllllll}
\hline & $1 \mathrm{a}$ & $2 \mathrm{a}$ & $2 \mathrm{~b}$ & $2 \mathrm{c}$ & $3 \mathrm{a}$ & $3 \mathrm{~b}$ \\
\hline GHGs concentrations in 2100 (ppme) & 942 & 633 & 521 & 492 & 563 & 460 \\
Highest level of GHGs concentrations, & 942 & 633 & 550 & 526 & 563 & 497 \\
2005-2100 (ppme) & & & & & &
\end{tabular}




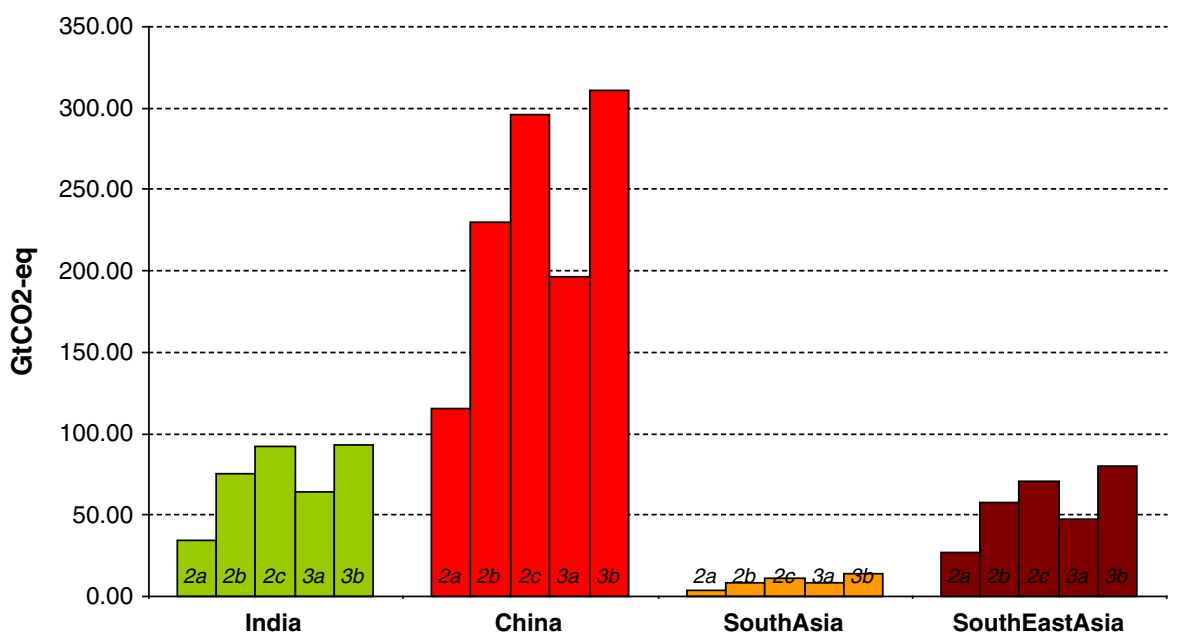

Fig. 2. Cumulative emissions abatement (2010 to 2050) in the developing Asia regions for the 5 AME policy scenarios.

Table 3 displays other measures of effort for the scenario $3 \mathrm{~b}$ in 2050. Despite Asian countries reducing total emissions less than the OECD with respect to 2005, they undertake a tremendous effort at per capita level. In 2050, the average Developing Asia citizen cannot afford to emit as much as in the OECD. The Gross Domestic Product (GDP) loss induced by the carbon tax (with lump-sum revenue recycling) is lower in the OECD than in China and in South-East Asia, with India falling shortly below. The income per capita gaps between developed and developing countries narrow in 2050 in the BaU scenario, but still remain wide. For example, China's and India's per capita income (measured in market exchange rates) are equal to only $30 \%$ and $10 \%$ of the average income in the $\mathrm{OECD}$, respectively. Therefore the same percentage GDP loss entails a much larger welfare burden in poorer economies.

Finally, we run a thought experiment and examine what would look like an economy in which carbon is taxed at extremely high prices and revenues are recycled lump sum. On average, each citizen will pay the carbon tax on her emissions (e.g. $1.3 \mathrm{tCO}_{2}$ in India) at the current carbon price. We define the ratio of carbon taxation over per capita income as the "carbon tax burden". The average Chinese citizen will pay roughly a quarter of her revenue in carbon taxes compared to only the $4 \%$ in the OECD. It is true that at the end of the month she will receive a check in the mail with a lump-sum transfer from the Government. However, the sheer size of the carbon tax is huge in Developing Asia and dominates all economic activities at personal and national level, a plausible source of confrontation, social unrest and a true managerial challenge.

Thus, the claim of developing countries that the G8/MEF proposal put forward in 2009 is not fair is actually confirmed by our modelling

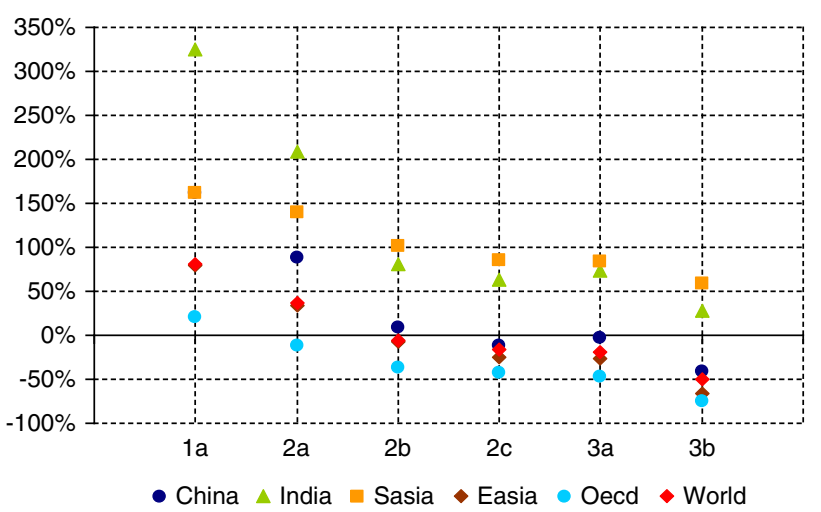

Fig. 3. Change in emissions in 2050 with respect to 2005 in the developing Asia regions for the 5 AME policy scenarios. experiment. An alternative that would preserve efficiency but would allow for a more equally distributed commitment is of course that of implementing the climate policy not through equal, domestic carbon taxes, but rather through a quota system with the possibility to trade $\mathrm{CO}_{2}$ permit allowances. This is itself plagued by several deficiencies, and in the next section we turn to the discussion of trading schemes and on whether and how it is possible to find a compromise between efficiency and equity.

\section{The Asian Trading Scheme (ATS)}

In Section 3 we highlighted the importance of the Asian region for both the climate change problem and for its solution. According to the scenarios generated by the WITCH model, by mid-century developing Asia will account for more than $40 \%$ of global GHGs emissions. In the same year, and across all the climate policy scenarios considered thus far, developing Asia would also account for roughly 50\% of global mitigation of GHGs. This simple snapshot emphasizes the importance of involving the region into the global effort of climate mitigation, or otherwise it won't be effective.

However, our analysis has also shown that achieving stringent climate stabilization targets such as those compatible with limiting temperature increase below $2{ }^{\circ} \mathrm{C}$ (scenario $3 \mathrm{~b}$ here) by means of homogenous carbon taxation across regions without redistributionsimilarly to what proposed at the policy level by the industrialized nations-is likely to be incompatible with a reasonable definition of just allocation of effort. As a result, it is unlikely to be endorsed by the developing Asian countries.

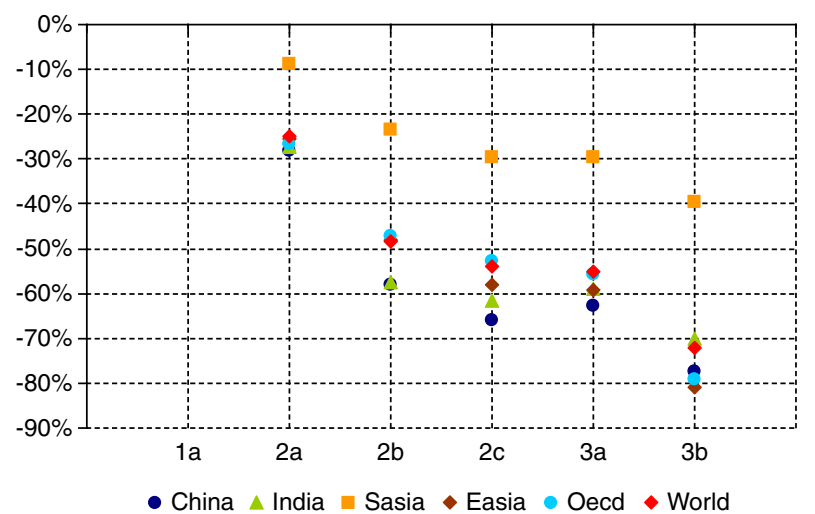

Fig. 4. Change in emissions in 2050 with respect to the $\mathrm{BaU}$ in the developing Asia regions for the 5 AME policy scenarios. 
Table 3

Indicators of effort for the scenario $3 \mathrm{~b}$ in 2050 across regions.

\begin{tabular}{lcccccc}
\hline & China India & $\begin{array}{l}\text { South } \\
\text { Asia }\end{array}$ & $\begin{array}{l}\text { South- } \\
\text { East } \\
\text { Asia }\end{array}$ & & \\
\hline $\begin{array}{c}\text { Emissions per capita } \\
\left(\mathrm{tCO}_{2} \text {-eq/cap }\right)\end{array}$ \\
$\begin{array}{c}\mathrm{GDP} \text { losses in } 2050 \\
\quad \% \text { change wrt the BaU) }\end{array}$ & 3.1 & 1.3 & 1.9 & 1.2 & 3.6 & 2.4 \\
$\begin{array}{c}\text { Carbon tax burden } \\
(\text { carbon tax as \% of per cap income) }\end{array}$ & $27 \%$ & $11 \%$ & $23 \%$ & $6 \%$ & $4 \%$ & $9 \%$ \\
\hline
\end{tabular}

Two potential solutions can be envisaged as a way out of this impasse. One possibility would be to keep abatement domestic, but diversify the level of effort by differentiating the carbon taxes, with higher values in the developed countries and lower in the developed ones. This, however, would come at the cost of efficiency: by no longer equalizing the marginal abatement costs, the global economic cost of the policy would be higher. Given the potentially high costs required to achieve stringent climate targets, this doesn't seem a palatable option. The alternative would be to keep equalizing marginal abetment costs by implementing a quota system in which allowances of $\mathrm{CO}_{2}$ permits can be traded among countries, the mechanism promoted in the Kyoto protocol. A well-designed, global cap-and-trade system has the potential to create the right incentives to engage developing countries (Frankel, 2008).

However, this last policy instrument is also subject to a series of limitations. It could involve potentially large financial transfers across countries. These flows might be substantial and arguably controversial. For example, De Cian and Tavoni (2011) found that the size of northsouth side-payments would be very sizeable, and that restrictions on $\mathrm{CO}_{2}$ trading would likely result. Furthermore, a well-functioning carbon market requires a solid infrastructure that guarantees the integrity of the transactions and provides market participants with reliable information. Issues of monitoring, reporting, and verification would emerge, and in this respect the experience with the Clean Development Mechanism (CDM) has not been encouraging (Wara and Victor, 2008). Solving these issue might take a long time and is likely to delay the establishment of a global carbon market.

The alternative that we set to analyze in the remaining of the paper is a compromise between efficiency and equity that foresees the regionalization of carbon markets. Although this is not a new concept, to our knowledge it has mostly been analyzed for the case of Europe and the US (e.g. linkage of the European Union Emission Trading Scheme and the regional or federal US proposed systems), but never for developing Asia (Flachsland et al., 2008; Gruell and Taschini, 2010; Jaffe and Stavins, 2008; Metcalf and Weisbach, 2010; Sterk et al., 2009; Tuerk et al., 2009). Specifically, we study the case of two separate carbon markets: one that would be exclusive to developing Asian countries (China, India, South Asia and South-East Asia), and another one for the rest of the world.

Carbon permits cannot be exchanged within these two markets. Thus, two prices of $\mathrm{CO}_{2}$ are likely to emerge, with a consequent loss of efficiency. Nevertheless, this loss is likely to be smaller than the case of the differentiated carbon prices region by region, since considerable trading of emission permits among regions in the two markets would occur nonetheless. In addition, in a world with multiple externalities, it is possible that these efficiency losses due to the misallocation of abatement could be compensated by a correction of the distortion due to the technology spillovers. For example, using the same model, De Cian and Tavoni (2011) have shown that mild restrictions on the use of international carbon offsets would induce only moderate losses of efficiency.

In order to implement this scheme, the WITCH model has been modified to accommodate two emission trading schemes (ETS). The iterative process now adjusts both prices to find an equilibrium

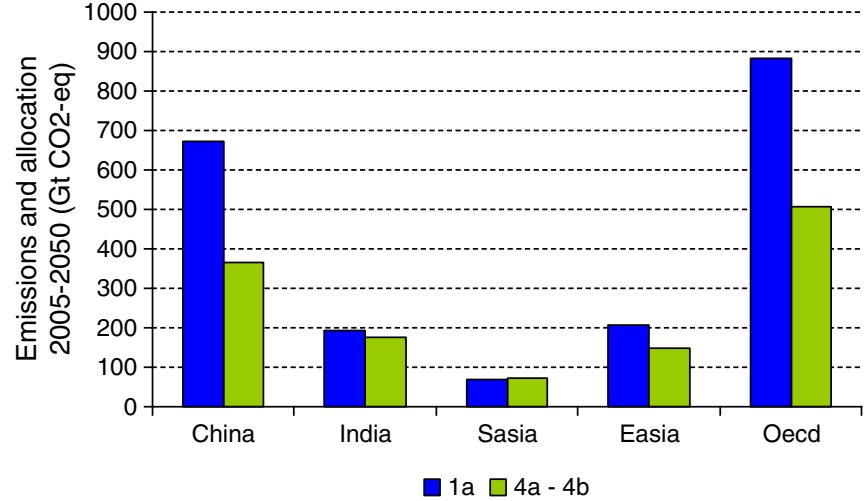

Fig. 5. Cumulative carbon budget (2005 to 2050) for the C\&C allocation scheme in comparison with cumulative emissions in the BaU.

between demand and supply. With this set-up, we can compare the case of a quota system with a global carbon market (scenario 4a) and with two regional markets (Asia and Rest of the World ETS, scenario $4 \mathrm{~b}$ ). We consider the same overall climate objective as in scenario 3b, namely the most stringent $2.6 \mathrm{~W} / \mathrm{m}^{2}$ (roughly $450 \mathrm{ppm}-\mathrm{eq}$ ), which is also the one most widely discussed in policy. Regarding the rule for allocating $\mathrm{CO}_{2}$ allowances to regions, a crucial input to the analysis, we choose the contraction and convergence one $(\mathrm{C} \& \mathrm{C})$ : with this rule emission permits are initially allocated on the basis of historic emissions; after a gradual transition, permits are allocated on the basis of population (equal-per-capita) in 2050 (Meyer, 2000). Although this is a recognized scheme that has been widely applied, many others could be considered. Because the distribution of abatement, and therefore the price of carbon in the market, is largely independent from the allocation of permits, alternative rules would only change the net position of a region in the market.

The carbon budget consistent with this scheme is shown in Fig. 5 face to face with the case of the BaU. It stands clear that substantial emission reductions would be needed by the OECD, China and to a less extent South-East Asia. For the poorer (in $\mathrm{CO}_{2}$ per capita terms) Asian countries, India and South Asia, the scheme would require essentially no cumulated abatement in the first half of the century.

\section{A numerical economic assessment of the ATS}

We begin the numerical evaluation of the Asia ETS by examining the path of carbon prices in the two scenarios, as reported in Fig. 6. The figure shows that in the case of two carbon markets, two quite distinctive set of prices emerge: the Asian market has a price which is essentially zero till 2035, and till 2050 remains lower than the unique price that is set in the global carbon market (scenario 4a, which is obviously equal to the carbon tax in scenario $3 \mathrm{~b}$ ). On the other hand, the carbon price in the ETS for OECD countries and the Rest of the World (RoW) market is higher. The 'exchange rate' between the two carbon prices in scenario $4 \mathrm{~b}$ changes over time, as the Asian carbon permits appreciate with respect to the non Asian ones, and actually cross them in value in the second half of the century (not shown in the figure). But for the whole next 40 years, the marginal cost of $\mathrm{CO}_{2}$ remains lower in the developing Asia region, because of its overall milder commitment and its plentiful abatement opportunities. This result goes into the aimed direction of differentiating the abatement costs in favour of the less developed countries. ${ }^{5}$

\footnotetext{
5 It should be noted that developing countries outside Asia would on the other hand be subject to a higher marginal cost. The implications for their economies, though, depend on the allocation: the higher price is indeed likely to be beneficial whenever, as for the case of this scheme, these countries are net sellers of permits.
} 


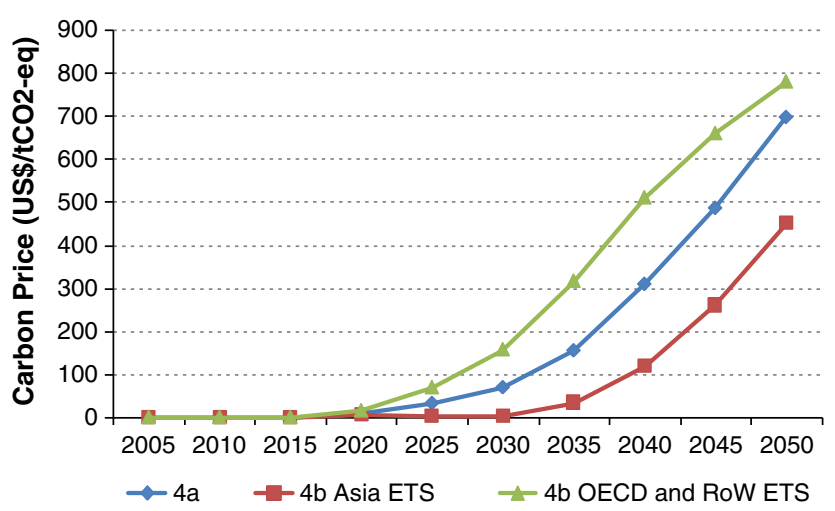

Fig. 6. Carbon permit prices for the quota scenarios 4a and 4b.

The two different markets also change the trading positions and associated financial transfers across countries. Fig. 7 provides information on the inflows and outflows in the carbon market for the only developing Asian countries, in the case of a single and of two carbon markets. The figure shows that the big sellers of permits (India, East Asia and South-East Asia) would receive very sizeable financial transfers in exchange of emission mitigation, of up to 2 trillion USD in 2050. Such a figure is significantly reduced in the case of the Asia ETS, both as a consequence of the lower price of permits seen above, but also because of the lower demand, which in this case would come only from China and not from the industrialized countries. For example, the three selling regions in Asia sell in $20503.2 \mathrm{GtCO}_{2}$ in the case of a global market, and $1.9 \mathrm{GtCO}_{2}$ in the case of the Asia ETS. China increases the share of abatement abroad because without the competition of high income countries emissions allowances from other Asian countries become cheaper.

As expected, this has implications at the macroeconomic level. Fig. 8 reports the percentage deviation of GDP from its BaU level, in the 4a scenario (global cap-and-trade) and in the 4b scenario (Asia ETS). The left panel considers 2050 alone, the right panel considers discounted GDP change over the 2015-2050 time interval. With the Asia ETS South Asia (SASIA) and India still have benefits, but considerably smaller than in the global trade scenario. The Asia ETS reduces the cost of reaching the mitigation target by nearly $20 \%$ in China, in 2050. Cumulative discounted costs decrease by about $30 \%$. With the Asia ETS, East Asia (EASIA) lacks instead a sufficiently wide outlet for the emissions credits that the region can generate with avoided deforestation and afforestation activities. As a result we find that EASIA suffers from (small) net costs in 2050. If we consider a longer time horizon the position of EASIA remains mostly unchanged. Interestingly, the cost for OECD economies remains largely unaffected in 2050. Costs increase instead from $1.0 \%$ to $1.4 \%$ over the 2015-2050 time horizon. As for the RoW, at mid-century they are one of the largest beneficiaries of the carbon market separation, with a gain of about $20 \%$. Still positive, even if less pronounced, is the impact over 2015-2050. Yet, GDP losses remain high, mostly as a result of the terms of trade losses of energy exporting countries whose falls in oil revenues bear large macroeconomic consequences. The cost reductions in 2050 are mostly a result of the larger sales of carbon of regions such as Sub-Saharan Africa and Latina America, who have abundant resources of land use mitigation options, including ones that allow absorbing $\mathrm{CO}_{2}$ from the atmosphere (such as BECCS). At global level, in 2050, the cost of climate policy does not change when there are two separate markets; discounted costs increase by $15 \%$.

This result is quite powerful and indicates that developing Asia can be considered self-sufficient in terms of emission allowances. It is therefore conceivable to create a developing Asia "bubble" that allows a regional redistribution of a macro-regional target, as it happens now for the European Union. It is of course possible to conceive more complex, welfare enhancing, allocations of the regional target than the one considered in this study. The choice of the regional distribution would be more flexible, managed at regional level and adjusted over time.

Fig. 9 expands the analysis of two separate carbon markets on global GDP. The chart shows that the efficiency loss is rather small till 2065, though it rapidly increases in the late part of the century when emission reduction targets become ambitious and policy costs are very substantial: as a result, the reduced flexibility in abating emissions due to the market separation generates a higher penalty. One might well conceive, though, that the two markets could merge at some point, especially given the long time frame analysed here. Thus, from a policy view point the most important result from this chart is that, at least globally, splitting the global carbon market in two large sub-units has a relatively modest cost until $2050 .^{6}$

Finally, one of the main advantages of creating a regional market for emissions allowances is in fact the possibility of fostering cooperation among developing Asia countries. Regional climate negotiations might include many other issues, like technological and economic cooperation, intra-regional trade, etc.

By linking climate and other issues it is possible to strengthen the stability of the developing Asia coalition and to enhance its role in the global negotiation game (see for example Barrett, 1997; Carraro and Siniscalco, 1995, 1997; Cesar and de Zeeuw, 1996; Folmer et al., 1993). It should be remarked, though, that the Asia ETS would only partially address the incentive compatibility of climate cooperation. For some countries, such as India and South Asia, the policy benefits would be lessened. Previous analysis with the same model used in this paper has indeed shown that creating self sustaining climate coalitions which are stable and effective is very difficult (Bosetti et al., 2009).

\section{Discussion and conclusions}

The active participation of developing Asia to the international effort to control global warming is crucial. The largest fraction of the incremental growth of GHGs is expected to come from the developing countries of Asia. If the present trend is not changed, it will be impossible to achieve even moderate climate policy targets.

In fact, the world is asking developing Asia to engage in extremely ambitious emission reduction policies. This paper shows that the G8 and MEF pledge to reduce global emissions by $50 \%$ in 2050 implicitly assumes that developing Asia must cut emissions by $70-80 \%$ with respect to the BaU scenario. The size of the contraction needed with respect to the $\mathrm{BaU}$ is a good indicator of the level of effort required to fast growing developing economies.

This paper also examines other indicators of the stringency of the 2050 target. Emissions per capita, the "tax burden", the macroeconomic GDP loss, indicate that the distribution of effort implied by the G8 and the MEF target falls disproportionately on developing Asia and other developing nations. Since G8 countries have already committed to severe emission reductions, our analysis shows that the pledge to reduce global emissions by $50 \%$ in 2050 is extremely ambitious.

There is without doubts a trade-off between an equitable burden sharing and the climate objective. It is therefore of utmost importance to refocus the discussion on equitable and realistic distribution of effort.

Ideally, any global stabilization target can be achieved by means of any distribution of international emission permits, if global trade is allowed. The market guarantees an efficient solution, independently from the initial distribution. However, it is hard to conceive that a global carbon market will exist in the first half of the century. The

\footnotetext{
${ }^{6}$ Between 2050 and 2065, a gain is observed. This is not surprising, given that the WITCH model features multiple externalities and is thus consistent with potential policy induces welfare improvements.
} 


\section{a) Global ETS}

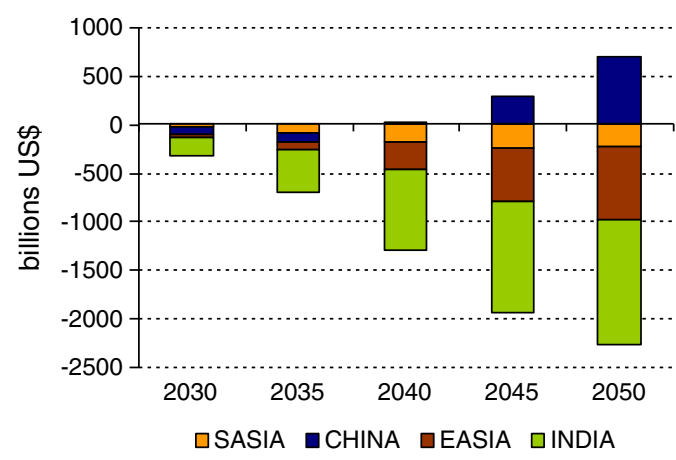

b) Asia ETS

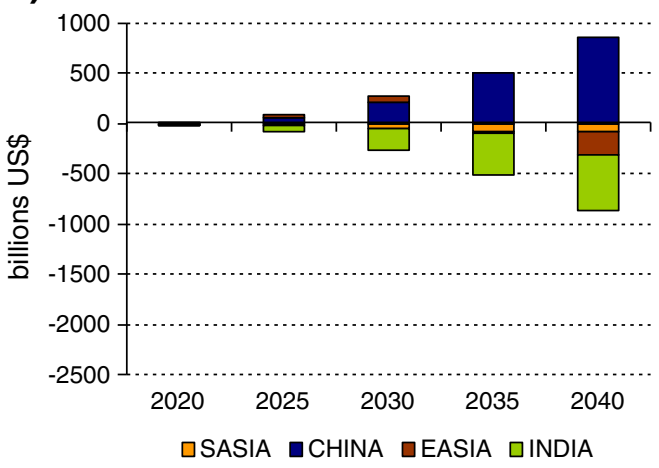

Fig. 7. Financial transfers (positive is buying, negative selling) for the Asian regions in the two scenarios.

financial flows towards developing countries might be unsustainable from a political and economic point of view. In addition, it will be hard to ensure a smooth and transparent functioning of the market for the obvious difficulties in monitoring and verification of the emission credits. A solution with only autarchic action, which however takes care of equity issues, is equally not desirable because of the inefficiencies that arise as a consequence of very large disparities among carbon prices internationally.

For those reasons many advocate the creation of regional carbon markets, with the possibility to link them with different degrees of interconnection. This paper contributes to this literature by introducing the concept and assessing the potential of a developing Asia Emission Trading Scheme (Asia ATS). We envision the creation of an Asian "bubble" that is distributed among countries at a regional negotiation level. The Asia ATS would resemble very much the European Emissions Trading Scheme (EU-ETS).

This paper shows that the advantages of building a regional market for emissions in Asia are many. First, under a contractionand-convergence allocation scheme, which was used as a prototype for a fair international allocation of effort, developing Asia appears to be self-sufficient with respect to the rest of the world, at least until 2050. Thus, treating developing Asia as a single block in international negotiations would not create large international unbalances. Second, the reduced competition for cheap abatement opportunities in Asia reduces the price of carbon in the region. This has obvious beneficial consequences for China, which is the regional net importer of emission credits. It has however also indirect beneficial implications for the large exporters of emission permits: a lower price and lower volumes in the market reduce the financial inflows in exporting countries to a politically and economically acceptable level. Third, the Asia ETS increases only marginally the cost of climate policy in OECD economies, which increases the political acceptability of this scheme. Finally, a regional emissions "bubble" would foster cooperation among developing Asia countries.
Issue linkage would become more concretely possible, given the many areas of cooperation that already exist among many countries in the region.

China is going to be the large regional leader in the future and will also play a major role in the Asia ETS. Being the country with the higher level of per capita emissions and one of the highest levels of income per capita, China would be a net buyer in the market. Without the interference of OECD economies it would enjoy greater access to regional cheap abatement opportunities and reduce considerably mitigation costs. At the same time, China would have a unique possibility to contribute to the regional development. Large, CDMlike, emission reductions project might be associated to bi-lateral agreements on economic and technological cooperation. At the same time China would also have greater responsibilities. From being a follower in global climate policy, it would become a leader of the regional climate policy, with all the burden to monitor and verify regional progresses.

Some caveats apply to our analysis. First, we used a very simplified allocation scheme. Many others are possible and the research of the Pareto optimal allocation is left for future research. Second, the Asia ETS might not be implementable due to the lack of sufficiently strong regional institutions. The confrontation on distribution issues might exacerbate, rather than alleviate, regional contrapositions, especially between China and India. Third, our analysis deals only with the first part of the century. Preliminary results show that developing Asia might become a net importer of emission permits as the stringency of the target increases enormously at the end of the century.

\section{Acknowledgements}

This paper is part of the research work being carried out by the Sustainable Development Programme at the Fondazione Eni Enrico Mattei and by the Climate Impacts and Policy Division of the EuroMediterranean Centre on Climate Change. Financial support under
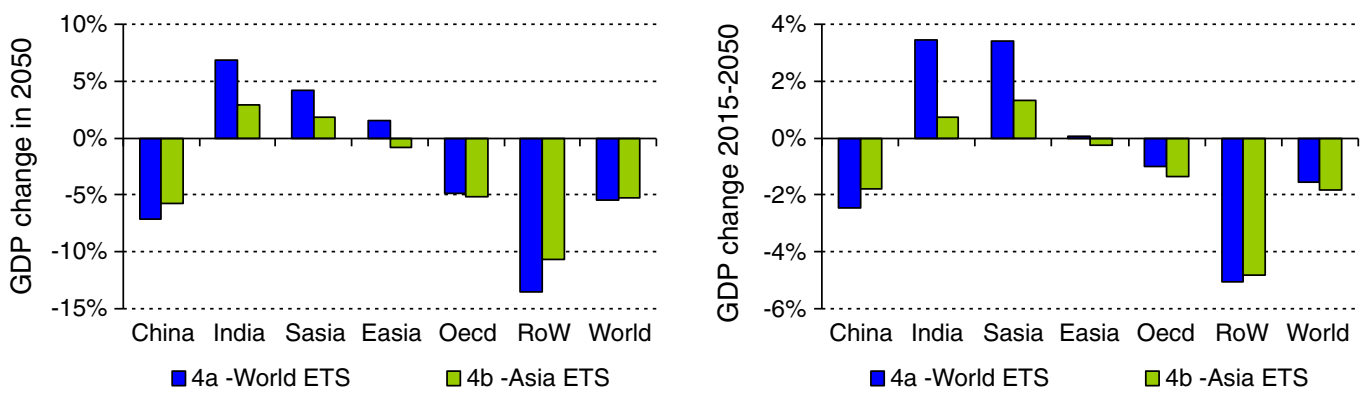

Fig. 8. GDP change with respect to BaU in 2050 for the two trading schemes. 3\% discount rate used for cumulative GDP cost. 


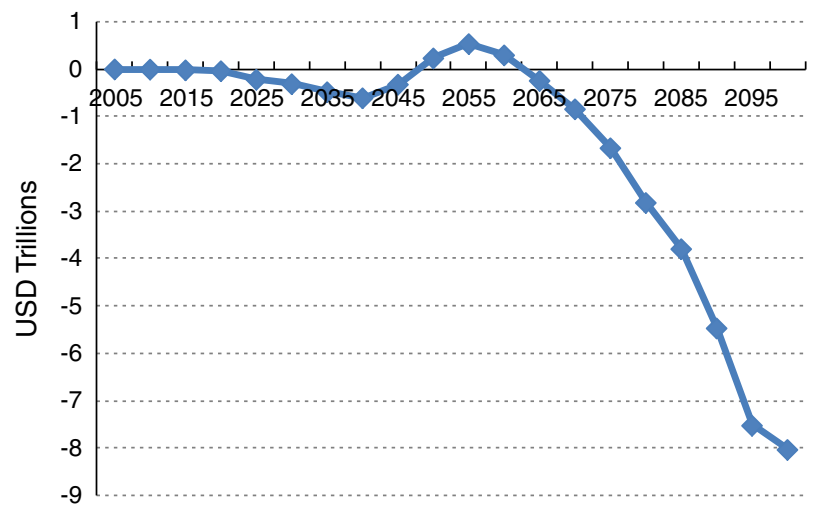

Fig. 9. Global policy cost differences between the global and the regional carbon market scenarios (expressed as change in GDP losses, USD trillions). Negative figures indicate that the global market is cheaper than the regionalized one, and vice versa.

the Climate Policy Outreach project, from the European Community's Seventh Framework Programme (FP7/2007-2013) under grant agreement no. 244766-PASHMINA (PAradigm SHifts Modelling and INnovative Approaches) and the EC2 Europe-China Clean Energy Centre is gratefully acknowledged.

\section{References}

Azar, C., Lindgren, K., Larson, E., Möllersten, K., 2006. Carbon capture and storage from fossil fuels and biomass-costs and potential role in stabilizing the atmosphere. Clim. Chang. 74 (1-3), 47-79.

Azar, C., Lindgren, K., Obersteiner, M., Riahi, K., van Vuuren, D.P., den Elzen, M., Möllersten, K., Larson, E., 2010. The feasibility of low CO2 concentration targets and the role of bio-energy with carbon capture and storage (BECCS). Clim. Chang. 100 (1), 195-202.

Barrett, S., 1997. The strategy of trade sanctions in international environmental agreements. Resour. Energy Econ. 19 (4), 345-361.

Bosetti, V., Carraro, C., Galeotti, M., Massetti, E., Tavoni, M., 2006. WITCH: A World Induced Technical Change Hybrid Model. The Energy Journal, Special Issue: Hybrid Modeling of Energy-Environment Policies: Reconciling Bottom-up and Top-down, pp. 13-38.

Bosetti, V., Carraro, C., De Cian, E., Duval, R., Massetti, E., Tavoni, M., 2009. The incentives to participate in and the stability of international climate coalitions: a game-theoretic approach using the WITCH model. OECD Economics Department Working Papers No. 702. June.

Calvin, K. et al., this issue. The role of Asia in mitigating climate change: results from the Asia Modelling Exercise. Energy Economics.

Carraro, C., Massetti, E., 2011. Energy and climate change in China. FEEM Nota di Lavoro No. 16. 2011. February.

Carraro, C., Siniscalco, D., 1995. Policy coordination for sustainability: commitments, transfers, and linked negotiations. In: Goldin, I., Winters, A. (Eds.), The Economics of Sustainable Development. Cambridge University Press, Cambridge.
Carraro, C., Siniscalco, D., 1997. R\&D cooperation and the stability of international environmental agreements. In: Carraro, C. (Ed.), International Environmental Agreements: Strategic Policy Issues. E. Elgar, Cheltenham.

Cesar, H., De Zeeuw, A., 1996. Issue linkage in global environmental problems. In: Xepapadeas, A. (Ed.), Economic Policy for the Environment and Natural Resources. E. Elgar, Cheltenham.

Clarke, L.E., Edmonds, J.A., Krey, V., Richels, R.G., Rose, S., Tavoni, M., 2009. International climate policy architectures: overview of the EMF22 international scenarios. Energy Econ. 31, S64-S81.

De Cian, E., Tavoni, M., 2011. Do technology externalities justify restrictions on emission permit trading? Fondazion Eni Enrico Mattei, mimeo.

Flachsland, C., Marschinski, R., Edenhofer, O., 2008. Global trading versus linking: architectures for international emissions trading. Potsdam Institute for Climate Impact Research, Working Paper. Sept.

Folmer, H., van Mouche, P., Ragland, S., 1993. Interconnected games and international environmental problems. Environ. Resour. Econ. 3, 313-335.

Frankel, J., 2008. An elaborated proposal for global climate policy architecture: specific formulas and emission targets for all countries in all decades. In: Aldy, J.E., Stavins, R.N. (Eds.), Post-Kyoto International Climate Policy. Cambridge University Press, Cambridge, United Kingdom and New York, NY, USA.

Gough, C., Upham, P., 2010. Biomass energy with carbon capture and storage (BECCS): a review. Tyndall Working Paper 147. Dec 2010.

Gruell, G., Taschini, L., 2010. Linking emission trading schemes. Available at SSRN. Feb 2010.

Hansson, J., Berndes, G., Johnsson, F., Kjärstad, J., 2009. Co-firing biomass with coal for electricity generation-an assessment of the potential in EU27. Energy Policy 37 (4), 1444-1455.

Havlík, P., Schneider, U.A., Schmid, E., Böttcher, H., Fritz, S., Skalský, R., Aoki, K., De Cara, S., Kindermann, G., Kraxner, F., Leduc, S., McCallum, I., Mosnier, A., Sauer, T. Obersteiner, M., 2010. Global land-use implications of first and second generation biofuel targets. Energy Policy 39 (10), 5690-5702.

IEAGHG, 2009. Biomass CCS Study IEA Greenhouse Gas R\&D Programme.

Jaffe, J., Stavins, R.N., 2008. Linkage of tradable permit systems in international climate policy architecture. Discussion Paper 08-07, Harvard Project on International Climate Agreements. Sept.

Massetti, E., 2011. Carbon tax scenarios for China and India: exploring politically feasible mitigation goals. International Environmental Agreements, Law, Economics and Politics, Special Issue: Reconciling Domestic Energy Needs and Global Climate Policy: Challenges and Opportunities for China and India, 11(3), pp. 209-227.

Metcalf, G.E., Weisbach, D., 2010. Linking policies when tastes differ: global climate policy in a heterogeneous world. Discussion Paper 2010-38, Harvard Project on International Climate Agreements, Belfer Center for Science and International Affairs, Harvard Kennedy School. Jul 2010.

Meyer, A., 2000. Contraction and convergence-the global solution to climate change. Global Commons Institute, Schumacher Briefing No.5.

Rhodes, J.S., Keith, D.W., 2005. Engineering economic analysis of biomass IGCC with carbon capture and storage. Biomass Bioenergy 29 (6), 440-450.

Sterk, W., Mehling, M., Tuerk, A., 2009. Prospects of linking EU and US emission trading schemes: comparing the Western Climate Initiative, the Waxman-Markey and the Lieberman-Warner Proposals. Climate Strategies Working Paper. April 2009.

Tavoni, M., Tol, R., 2010. Counting only the hits: the risk of underestimating the costs of stringent climate policies. Clim. Chang. 100, 769-778.

Tavoni, M., Chakravarty, S., Socolow, R., 2011. Safe vs. fair: a formidable trade-off in tackling climate change. FEEM Working Paper 2011.061.

Tuerk, A., Sterk, W., Haites, W., Mehling, M., Flachsland, C., Betz, R., Jotzo, F., 2009. Linking emissions trading schemes. Climate Strategies. May.

Wara, M.W., Victor, D.G., 2008. A realistic policy on International carbon offsets. PSED Working paper no. 74 